\title{
Jogos de estratégia de computador: hipertextualizando a geografia
}

\section{Strategic computer games: hipertextualizing geographic}

Alides Baptista Chimin Junio

Carla Silvia Pimentel

Universidade Estadual de Ponta Grossa

\begin{abstract}
Resumo: Este trabalho apresenta uma análise dos aspectos geográficos contidos no jogo de estratégia de computador Age of Empires II, da Microsoft. As análises partem do pressuposto de que o jogo é um hipertexto que oferece possibilidades de aprendizagem de noções e conceitos relativos ao espaço geográfico, contendo assim valor pedagógico para o ensino de Geografia. Destacamos nas análises o poder de subjetivação de jogos e, nesse contexto, a influência da cultura da qual são originários.
\end{abstract}

Palavras-chave: Cultura. Jogos de estratégia. Hipertexto. Geografia.

\begin{abstract}
This work presents an analysis of the geographic aspects which appear on the strategic game from computers Age of Empires II, created by Microsoft. The analysis are based on supposition that the game is considered a hypertext which offers possibilities of learning such as notion and concepts related to geographic spaces attributing , in this way, pedagogical value for Geography teaching. The analysis detached the subjective power of the games and, in this context, the influence of the provinient culture of them.
\end{abstract}

Keywords: Culture. Strategic games. Hypertext. Geography.

\section{INTRODUÇÃO}

Os jogos de estratégia de computador estão cada vez mais acessíveis à população, atraindo pessoas de diferentes faixas etárias, mas adolescentes e jovens têm sido o público mais ávido por essa mídia. O uso de multimídias na produção desses jogos tem sido um forte fator dessa atração.

Diante do crescente interesse por esses jogos, investigamos, por meio de entrevistas, jogadores do município de Palmeira/ PR, na Lan House Golden Gate, em 2005, procurando identificar os principais jogos de estratégia praticados por esses sujeitos jogadores. A partir da coleta de dados, selecionamos o jogo mais citado para analisar o conhecimento geográfico que se apresenta nele.

Identificamos oito jogos mais praticados por esses sujeitos: Age of Empires II (Microsoft), Civilization II (Activision), Command \& Conquer (Westwood Studios Inc.), Comandos (Eidos Interactive), Dark Colony (Gametek), Warcraft III (Blizzard Entertainment), OSenhor dos Anéis (Team 17 Microprose) e Star Craft (Blizzard Entertainment). Constatamos que todos eram oriundos dos Estados Unidos, tendo como tema central a guerra. Esse dado 
possibilitou uma reflexão pautada na intencionalidade criadora desses jogos, ao relacionarmos o contexto dos jogos com sua cultura originária.

Entre esses oito jogos, identificamos que o jogo predileto do grupo era o Age of Empires II, da Microsoft. Feita tal identificação, iniciamos uma análise partindo do pressuposto de que o jogo de estratégia de computador é um hipertexto, e tínhamos como finalidade identificar os aspectos geográficos apresentados na dialética do jogo. Acreditamos que os elementos geográficos presentes na espacialização do jogo foram utilizados como objetos hipertextuais, ao simularem a realidade, interagindo de forma ativa com o sujeito jogador.

Compreendemos que esses jogos exercem forte influência no conhecimento dos sujeitos jogadores, conhecimento que engloba noções e conceitos geográficos. A partir dessa premissa buscamos destacar as possibilidades de aprendizagem geográfica expressas nessa mídia.

\section{O JOGO E SUA CULTURA ORIGINÁRIA}

O jogo de estratégia torna a Geografia um espetáculo que interage com o jogador. Mas essa Geografia espetáculo, caracterizada por Lacoste (1989) em outras situações, pode trazer uma armação ideológica muito forte de seus criadores. Essa comparação se dá pelo fato de que o jogo é desenvolvido para um público alvo como entretenimento, que se percebe assimilado com aspectos da Geografia. Porém, quando se trata de um espetáculo, sempre existirá aquele que cria o espetáculo e que irá expressar na criação seus valores (KELLNER, 2001). A expressão daquele que cria é construída dentro de uma sociedade, que irá trabalhar com o indivíduo transformando-o em um sujeito (MENDES, 2001). Em síntese, o jogo será a expressão da sociedade criadora, e através do seu estudo podemos perceber todo um aparato cultural de suas origens. Para Kellner (2001, p. 143),

os textos populares da mídia constituem um acesso principal às realidades sociais de sua era: assim, a sua interpretação possibilita a compreensão daquilo que está de fato acontecendo em determinada sociedade em dado momento.

O resultado dessa expressão social nos jogos causará influência na formação do sujeito, e é por isso que Kellner (2001) argumenta sobre a importância do estudo do contexto histórico da mídia, afirmando que sem essa análise qualquer pesquisa ficará incompleta.

Observando o quesito "nacionalidade do jogo", o qual nos direciona para a cultura originária, constatamos que todos os jogos citados pelos entrevistados provêm dos EUA. Com essa informação, optamos por realizar a análise proposta por Kellner (2001), e reconhecer o contexto dos jogos de estratégia de computador.

Ao fazer uma análise dos jogos de computador como forma de subjetivação, Mendes (2001) acaba chegando a uma análise política da cultura norte-americana. Para o referido autor, os jogos de computador são a segunda maior indústria de entretenimento dos EUA, perdendo apenas para a televisão. Esse grande investimento possui um objetivo, que para Mendes (2001) está fortemente relacionado à política do governo americano.

Observando o tema dos jogos citados pelos entrevistados, é possível constatar que todos eles representam contextos de guerras. Mendes (2001) afirma que os temas dos jogos de computador nos EUA são em sua grande maioria de guerra, e isso não é mera coincidência, pois eles são utilizados como forma de subjetivar aqueles que jogam. Para o referido autor, 
o governo dos EUA está, desde o final da Segunda Guerra Mundial, investindo em simuladores que pudessem treinar seus soldados para futuras guerras. O governo começou a trabalhar junto com as indústrias dos jogos, fornecendo informações para a produção desse entretenimento. Tal cooperação teria por finalidade legitimar atos militares americanos. $O$ fato de vários jovens estarem jogando ou vendo filmes de guerra faria incorporar-se culturalmente uma aceitação para a guerra. Essa relação cultural é argumentada por Freire (1982), quando afirma que o primeiro passo para dominar alguém culturalmente é fazer esse indivíduo enxergar a realidade com a ótica do invasor, ou seja, ele passa tanto tempo vendo e percebendo a guerra que acaba por incorporar esse fato a sua vida, considerando-o normal. Freud (apud KELLNER, 2001) explica que essas imagens ressonantes acabam influenciando o indivíduo em sua constituição como sujeito, designando a isso como paleossimbologismo ${ }^{1}$.

O trabalho de legitimação dos atos começa durante a Segunda Guerra Mundial, que, para Chomsky (1999), foi um verdadeiro divisor de águas. Esse autor explica que, apesar de a Segunda Guerra Mundial ter causado conseqüências em todo o mundo, foi apenas a Europa a verdadeira afetada pela destruição da guerra. E isso foi o solavanco para impulsionar a indústria americana, pois a Europa era a principal concorrente industrial dos Estados Unidos, que viu a chance de dominar um mercado arrasado pela guerra. Chomsky (1999) cita o Estudo de Planejamento Político (EPP 23) do governo americano, escrito em 1948, que tinha por finalidade planejar como dominar a "Grande Área". Eram tratados como "Grande Área” a Europa Ocidental, o Japão e o Terceiro Mundo. Destacamos um trecho interessante deste documento:

1 Conjunto de fatores decorrentes do passado que influenciam na formação do sujeito.
JOGOS DE ESTRATÉGIA DE COMPUTADORः HIPERTEXTUALIZANDO A GEOGRAFIA

Nós temos cerca de $50 \%$ da riqueza mundial, mas somente $6,3 \%$ de sua população [...]. Nesta situação, não podemos deixar de ser alvo de inveja e ressentimento. Nossa verdadeira tarefa, na próxima fase, é planejar um padrão de relações que nos permitirá manter esta posição de desigualdade [...] (KENNAN apud CHOMSKY, 1999, p. 12).

Segundo o autor, para o governo conseguir realizar seu objetivo, dominar a "Grande Área", seria preciso em primeiro lugar que sua própria população reconhecesse seus atos como corretos. Para isso, investiu-se nas mídias, com divulgação de slogans ou simplesmente manipulação das notícias, obscurecendo atos que seriam tomados com maus olhos pela população, $\mathrm{e}$ exagerando atos que causassem revoltas, a fim de legitimar os propósitos do governo. Em síntese, segundo Chomsky (1999), o governo americano tinha o objetivo, após a Segunda Guerra Mundial, de dominar a opinião pública para posteriormente dominar a "Grande Área".

É interessante compararmos essa análise com o que Yves Lacoste (1989) afirma sobre o uso da Geografia, principalmente nos países anglo-saxões, que seria o de fazer a guerra. Por isso essa ciência foi retirada dos currículos escolares desses países, incluindo-se os EUA, pois sua população deveria compreender o mínimo de suas ações. A exclusão da Geografia dos currículos desses países serviu como uma cortina de fumaça entre os olhos de sua população e as atitudes do governo.

Um exemplo do uso de informações externas distorcidas para manter a opinião pública favorável seria a Guerra Fria. Chomsky (1999) coloca este conflito como um acordo entre duas superpotências para controlar suas próprias populações. Os governos usavam notícias de crimes (absolutamente reais) de um país inimigo para legitimar seus atos. Os Estados Unidos mostravam a União Soviética como 
um monstro, e o governo seria o mocinho protegendo sua população contra os "tentáculos de ferro soviéticos", por meio de investimentos pesados na indústria de armas. O mesmo acontecia com a União Soviética, que mostrava os crimes dos Estados Unidos para legitimar seus atos de guerra. De acordo com o autor, as duas superpotências teriam dividido o mundo em duas partes: os Estados Unidos dominando os países do Terceiro Mundo, o Japão e a Europa Ocidental (a "Grande Área"), e a União Soviética dominando os países socialistas.

Com o fim da Guerra Fria, o governo Bush (1988) procurou outros inimigos para intimidar. Segundo Chomsky (1999), quando Bush entrou no governo, em 1988, a opinião pública apontava o maior problema do país como sendo o déficit do orçamento público, e apenas $3 \%$ da população apontavam as drogas. Isso foi considerado um grande problema, pois o governo já não estava mais conseguindo argumentação para legitimar suas ações e assim sua população começava a perceber os reais problemas sociais do país. Com o bombardeio da mídia sobre as drogas, os números se inverteram e elas passaram a ser apontadas como o maior problema no país por $40 \%$ a $45 \%$ da população.

\begin{abstract}
Atualmente, quando algum país aliado reclama que os EUA não estão enviando suficiente ajuda financeira, não diz mais 'necessitamos dela para conter os russos', e sim, 'necessitamos dela para reprimir o tráfico de drogas'. (CHOMSKY, 1999, p.107).
\end{abstract}

Com o fim da Guerra Fria, tudo indicaria que os Estados Unidos tenderiam a não mais investir como antes em orçamentos militares, mas o que percebemos foi o contrário. Chomsky (2003) aponta mais uma argumentação do governo para legitimar seus investimentos. No início da década de
90, com o fim da Guerra Fria, ao invés de observarmos um desarmamento, percebemos o contrário: os Estado Unidos fazem da Guerra do Golfo um verdadeiro show, mostrado ao vivo pela televisão. Agora não eram mais os soviéticos, surgia um novo vilão internacional perigosíssimo, o terrorismo. Segundo Chomsky (2003), o governo usou o ataque terrorista de 11 de setembro de 2001 para invadir o Iraque à procura de armas de destruição em massa. O posterior ataque ao Afeganistão e as notícias de bombas no Iraque, foram o suficientes para legitimar a retomada, pelo governo americano, do projeto Guerra nas Estrelas. Esse projeto tem por finalidade proteger o território americano contra possíveis ataques externos, ou seja, proteger os Estados Unidos do resto do mundo. Para Chomsky (2003), ele não teria sido retomado sem a campanha antiterrorista.

A análise feita até o momento mostra a pertinência do fato de as indústrias de jogos estarem trabalhando com apoio militar na produção de simuladores de guerra. Isso tem o intuito de criar uma legitimação de atos, ou seja, a familiarização com a guerra para uma melhor aceitação dela. Visto que todos os jogos citados pelos entrevistados utilizam temas de guerras, percebemos que o contexto histórico dos jogos de estratégia de computador está na legitimação militar dos Estados Unidos. $\mathrm{O}$ governo norte americano, afirma Kellner (2001), precisa investir em determinadas áreas de interesses próprios, criando campanhas na mídia para manter uma grande porcentagem de aceitação pública, para isso procura até mesmo utilizar as forças armadas, não como força, mas como forma ideológica, incentivando, inclusive, a criação de jogos de estratégias. Pelo fato de os Estados Unidos exercerem forte influência no mundo, eles acabam por exportar esse produto para muitos países, inclusive para o Brasil. Isso é decorrente de um fenômeno 
denominado globalização ou fragmentação (CASTELLS, 1999). Para esse autor, a globalização cria ligações culturais, econômicas, tecnológicas, comerciais pelo mundo todo, mas não faz isso de forma homogênea. Ela cria vínculos com determinadas instâncias sociais espalhadas pelo globo, excluindo aquelas que não possuem condições para essa globalização. São criadas "bolhas" nas sociedades, excluindo milhares de indivíduos. Por isso Castells (1999) chama a globalização de fragmentação.

\section{O JOGO COMO UM HIPERTEXTO}

Para Correia e Andrade (2004), a interatividade se dá em um ambiente constituído por uma interface, que no caso dos jogos é definida graficamente. A interface é o meio pelo qual ocorre o processo interativo, neste caso podendo ser o hardware, o software ou os dois. Assim, a interatividade é uma relação, uma conversação entre o sujeito jogador e a técnica, expressa por meio da interface. A interatividade digital é um contexto de comunicação, de troca, no qual homem, máquina e programas são "agentes" que assumem papéis.

Podemos compreender estas relações por meio da definição do que é o virtual. Diferentemente do que muitos pensam, o virtual não se opõe ao real, na verdade ele faz oposição ao atual. Para Lévy (2001), o virtual é aquilo que existe de potência e não de ato, já o atual existe de potência e de ato. Portanto o jogo comporta-se como objeto virtual, em certos momentos, e como atual, a partir do momento em que o sujeito jogador realiza uma ação. Já a cartografia, por exemplo, comporta-se unicamente como virtual, pois ela é criada e não pode ser atualizada pelo leitor, como ocorre com o jogador que pode manipular algumas ações nos jogos.

Albuquerque e Sá (2000) afirmam que, por existir a relação interativa, o jogo é um hipertexto. Colocando o jogo de forma contextualizada, percebe-se que ele seqüencia individualmente uma história para cada sujeito jogador. O fato de o usuário possuir certa "liberdade" para construir sua própria história no jogo é o fator principal que esses autores consideram para identificar o jogo como um hipertexto.

O hipertexto, para Correia e Andrade (2004), representa a falência do discurso tradicional lógico, acabado, fechado em si. Isso ocorre porque no hipertexto o leitor assume um papel ativo, sendo ao mesmo tempo co-autor. Para compreender isso, devemos analisar o que seria um hipertexto.

Albuquerque eSá (2000) descrevem o hipertexto como uma escrita não seqüencial, um texto que permite ao leitor a escolha, que se lê melhor em uma tela interativa, ou seja, como pedaços de textos conectados por links, que oferecem ao leitor diferentes caminhos. Para eles, o hipertexto seria "o 'texto ideal', inacabado e aberto, onde as redes sejam múltiplas e interajam [...]" (ALBUQUERQUE e SÁ, 2000, p. 86, grifo do autor). Para Lévy (1999), um hipertexto seria descrito como oposição ao texto linear, seria um texto que não obedece a uma seqüência lógica, sem início, meio e fim, que são definidos por um leitor. $O$ sujeito "participa, portanto, da redação do texto que lê." (LEEVY, 1999, p. 57)

Kerckhove (2003) estabelece uma diferenciação entre o texto e o hipertexto. Considera o texto algo definido, fechado por um autor com todos os seus conceitos de realidade. Afirma que "[...] livros e papéis propõem amplamente às pessoas os conteúdos de 'realidade' filtrados através da modalidade do texto." (2003, p. 8, grifo do autor). Já os hipertextos obedecem às necessidades do leitor para efetuar respostas às dúvidas momentâneas. $\mathrm{O}$ autor coloca que um hipertexto obedece a uma 
seqüência muito mais ampla, ligando o sujeito-leitor a uma não-linearidade, abrangendo desde a mente do leitor, suas necessidades de respostas, até as diversas respostas oferecidas pelo meio.

Kerckhove (2003) caracteriza a estrutura do hipertexto basicamente por links e nós. Os nós seriam pontos interligados pelos links (ligações), formando uma rede denominada hipertexto. Correia e Andrade (2004) explicam que os nós são unidades de informações em um hiperdocumento, que pode conter um ou mais tipos de dados: textos, figuras, fotos, sons, animações, códigos e outros. Já o link é o conceito básico mais importante do hipertexto. Os links fazem ligações entre um nó e outro. Quando ativamos um nó, um salto é feito, guiado pelo link até um documento que poderá possuir outros nós. A estrutura formada pelos nós e pelos links é denominada por Lévy (1993) como redes.

Um exemplo de rede seria a web. Percebemos que o sujeito não segue a estrutura definida por um autor, ele cria o texto que melhor lhe agrade, não havendo necessidade de compreender aquilo que não lhe interesse, pulando diretamente para o texto objetivado. Essa seria basicamente a estrutura de um hipertexto na web.

Os jogos, para Albuquerque e Sá (2000), são feitos de acordo com a lógica do programador, são totalmente influenciados pela sua cultura originária e assim se encontram limitados. Apesar de o jogo ser denominado de hipertexto por esses autores, eles deixam bem claro que esse hipertexto cria liberdades limitadas. Apesar de o jogador poder fazer muitas coisas no jogo, ele ainda possui um fim definido que é vencer o inimigo, ele precisa se enquadrar na lógica do jogo para assim visualizar múltiplas possibilidades para se chegar a um objetivo. Quando o sujeito cria o jogo, o faz de acordo com sua carga cultural, portanto, tudo aquilo que será feito dentro do jogo, por mais que o jogador tenha liberdade de fazer, foi planejado pelo criador. O jogo possui um início e um fim definidos, e entre esses dois pontos possuímos uma imensa rede hipertextual, porém condicionada.

Apesar de todas essas limitações, consideramos o jogo como um hipertexto, pois, para esses autores, o jogo não deixa de ter um contexto aberto para diferentes possibilidades de ação.

\section{A EDUCAÇÃO E A MÍDIA: O PROCESSO DE SUBJETIVAÇÃO}

Ao analisar os jogos, Mendes (2001), afirma que subjetivar é transformar um indivíduo em um sujeito. Dar personalidade através do convencimento, de aceitações; moldar um padrão de sujeitos aceitáveis para aquele que subjetiva, por meio de um conjunto seqüenciado de informações. Os jogos de computador trazem consigo toda uma carga cultural de suas origens, como visto anteriormente, e essa cultura presente no jogo interage com o indivíduo, fazendo-o conviver ativamente com determinados fatos, o que promove sua subjetivação. Kellner (2001) afirma que há uma relação entre duas culturas, quando lidamos um produto midiático. Uma cultura está no indivíduo receptor, que a adquiriu na convivência com seu meio familiar ${ }^{2}$, e a outra provém dos jogos, sendo considerada como uma cultura invasora por ser externa ao ambiente familiar do indivíduo, mas que acaba exercendo forte influência na formação desse indivíduo como sujeito.

2 Com "familiar", faz-se referência ao ambiente que cerca o indivíduo, como seus amigos, a escola, o trabalho, ou seja, todo o ambiente que se relaciona e o influencia em seu desenvolvimento como sujeito; podemos, é claro, incluir como parte dessa formação a sua própria família. 
Trata-se de uma invasão cultural, pois o jogo deixa sua simples ludicidade passiva e se torna um produto originário de uma sociedade com costumes e crenças que acabam por se interagir com o indivíduo jogador, subjetivando-o. Freire (1982) considera a invasão cultural uma violência à cultura invadida, pois aquela penetra na vida e inferioriza a cultura do invadido. Para Freire (1982, p.178), "a invasão cultural é a penetração que fazem os invasores no contexto cultural dos invadidos, impondo a estes sua visão do mundo, enquanto lhes freiam a criatividade, ao inibirem sua expansão".

Considerando a ótica de Freire (1982), a cultura invasora impõe todo seu aparato argumentativo, fazendo com que o invadido passe a enxergar o mundo com a visão do invasor. Dessa forma, podemos fazer uma primeira ligação, proposta por Kellner (2001), com a participação histórica da cultura americana na cultura dos jogos. Pois, como afirma o referido autor, o contexto cultural americano é o mesmo encontrado no contexto da mídia, fazendo uma ligação entre o sujeito e a cultura americana. Freire (1982) afirma que, ao impor a visão de mundo a um sujeito, a cultura dominante pode fazer o invadido ver sua cultura como vulgar, passando a aceitar a visão do invasor.

O problema relatado por Freire (1982) é que os invadidos são convencidos de sua inferioridade intrínseca e, assim, como são vulneráveis à cultura dominante, não podem se manifestar por igual, acabando por se pacificar, seguindo as regras do invasor e inferiorizando a suas regras, seus costumes e criando assim sujeitos culturalmente híbridos $^{3}$. Como as regras são ditas pelo invasor, e o invadido não possui poder comunicativo para alterá-la externamente, o invasor jamais deixará que o invadido ganhe forças. Como afirma Kellner (2001), os produtos culturais expressam as lutas de classes, e a classe dominante sempre estará procurando formas para manter sua posição favorável. Freire (1982, p.179) afirma que "quanto mais mimetizados fiquem os invadidos, melhor para a estabilidade dos invasores".

\section{O Sujeito Jogador}

Quando surgem esses seres híbridos nas escolas, nos lares, nas ruas, costuma-se tomá-los como seres estranhos. Em educação, muitos professores, como afirma Moran (1993), ignoram o conhecimento desses indivíduos, por se tratar de uma nova forma de pensar, uma forma que não usa apenas os métodos lineares da escrita, mas usa imagens, sons, sensações, que precisam ser compreendidas para posteriormente serem trabalhadas.

Moran (1993) faz uma interessante discussão sobre o ambiente multimídia. Ele inicia seu trabalho analisando os problemas causados pela multimídia no sujeito, e depois começa a fazer apontamentos positivos sobre essa nova tecnologia. Para o autor, somente críticas não constroem soluções, devemos primeiramente conhecer essa nova mídia, para então "domá-la", usando-a em nosso favor. Tentar ignorar esse fato ajuda a construir um abismo entre os sujeitos ligados a essas mídias e o educador. Vejamos como Moran (1993) explica um possível motivo para a atração dos sujeitos pelas mídias.

Tanto a ficção quanto a informação se transformam em espetáculo, em desejo de atrair o telespectador. Ambos mexem com nossos sentimentos, emoções. Se mexem é porque encontram algum tipo de resposta que estamos procurando, muitas vezes inconscientemente. A televisão e os outros meios não nos obrigam a 
Alides Baptista Chimin Junio; Carla Silvia Pimentel

vê-los, estabelecem 'acordos' tácitos, procuram descobrir e mostrar o que queremos. Como encontramos respostas, continuamos assistindo. (MORAN, 1993, p. 24).

Moran (1993) coloca ainda que, antes de educarmos os jovens, devemos educar os adultos, fazendo com que compreendam os jovens, passando a enxergar a realidade deles. Que passem a entender o que os jovens valorizam, para só depois trabalhar a realidade escolar. Compreender que o aluno é um ser que partilha de sentimentos e que precisa de um outro ser para compartilhar suas emoções, para ajudá-lo nessa realidade solitária criada pela tecnologia, que falsamente traz a sensação de união, mas que na verdade é a interação com uma máquina fria e projetada por uma cultura indiferente à realidade do aluno.

Para Moran (1993), o indivíduo expressa seus sentimentos, seus conhecimentos, suas vontades com uma máquina politizada por uma cultura capitalista, que tem como único fim o lucro. Criticar quem joga é aumentar ainda mais o abismo entre o educador e o aluno, pois este confia na mídia, que lhe oferece respostas audiovisuais. Para esse autor, devemos conhecer criticamente essas mídias, para assim compreendermos o sujeito que faz uso delas. Assim, teremos a chance de interagir com o sujeito e direcionar seu conhecimento para uma cultura com ideais mais justos para a sociedade.

Para Freire (1982, p.189), “a sociedade simplesmente modernizada, mas não desenvolvida, continua dependente do centro externo, mesmo que assuma, por mera delegação, algumas áreas mínimas de decisão." Com base nessa afirmação, concluímos que não basta modernizar a sociedade, mas devemos conhecer a tecnologia e seu contexto histórico-cultural para não nos deixarmos dominar por ela.

\section{O JOGO AGE OF EMPIRES II}

Ao reconhecermos a influência que a tecnologia, por meio de mídias (principalmente as interativas), exerce nos jovens, buscamos analisar o jogo Age of Empires II, principalmente os aspectos geográficos hipertextualizados nele, com o propósito de demonstrar que é possível aprender e ensinar noções que permeiam os saberes científicos escolares utilizando mídias com as quais os alunos têm contato fora do âmbito escolar.

No jogo Age of Empires II, constatamos a presença de muitos símbolos representando algo na realidade do jogo. Percebemos a hipertextualização desses símbolos, que se comportam como nós fazendo links no jogo, pois, além de representar algo na realidade do jogo, tais símbolos realizam uma ação no jogo. O jogador pode selecionar um soldado nos menus e em seguida mandá-lo para determinado lugar na tela do jogo. Nessa ação é possível reconhecer o que foi observado por Albuquerque e Sá (2000) sobre a interferência do jogador no contexto do jogo.

Também podemos observar no jogo o caminho oposto ao descrito acima. Acabamos de observar que o símbolo possibilitou um ato no jogo. Contudo existe no jogo também o oposto, que é a realidade do jogo fazendo referência ao símbolo.

Quando observamos o canto superior direito da tela do jogo, percebemos a presença de cinco valores junto a símbolos. $\mathrm{O}$ primeiro faz referência à quantidade de madeira. O segundo representa a quantidade de alimento. $O$ terceiro, a quantidade de ouro. O quarto, a quantidade de pedra. O último símbolo é um dado populacional, que indica quantos escravos e soldados o jogador possui, e também o limite populacional que é possível adquirir com os atuais recursos.

Os valores descritos acima são utilizados durante o jogo de forma que o jogador 
adquira produtos e, com isso, tenha a possibilidade de melhorar a estruturação de sua aldeia, armar melhor seus soldados, comprar soldados, evoluir no tempo e comprar escravos. Para a aquisição desses valores (ouro, pedra, madeira, alimento), o jogador faz uso dos seus escravos, que exploram o local e coletam os produtos que estão em lugares indeterminados do jogo. Com os valores acumulados, os escravos podem construir a estrutura da aldeia de acordo com o valor de cada construção. Cada construção é responsável pela produção de algo, como soldados ou equipamentos. Observamos que, ao ser selecionado o escravo, surge no menu um conjunto de símbolos. Quando optamos por determinado símbolo é automaticamente descontado seu valor na tabela de recursos explorados e acumulados (ouro, pedra, madeira, alimento), liberando-se a ação do escravo, conseguindo-se permissão para construir a estrutura desejada.

No decorrer do jogo, a acumulação desses produtos faz surgir a possibilidade de passar a um próximo período de evolução, por exemplo. Ojogo se inicia no período da pedra lascada e, no seu desenrolar, podemos, com um valor determinado, passar a um próximo período, que fará surgir a possibilidade de produzir um exército mais forte que o exército do período anterior.

Destacamos também que, quando selecionado, cada personagem do jogo possui um menu diferente. No menu do escravo surgirão opções como a construção de edifícios ou exploração de determinado material, como a madeira, ou até mesmo a produção de alimento. O menu dos soldados nos permite apenas ordenar o ataque ao inimigo ou o patrulhamento de determinada área. Com a exploração do jogo, surge a possibilidade de explorar madeira, ouro, pedras e alimentos que posteriormente são convertidos em estruturas e exércitos.
JOGOS DE ESTRATÉGIA DE COMPUTADOR: HIPERTEXTUALIZANDO A GEOGRAFIA

\section{A Geografia no jogo Age of Empires II}

\section{Abordagem conceitual}

A partir da análise do jogo, podemos identificar a expressão dos conceitos geográficos de espaço, paisagem, região e território. $\mathrm{O}$ espaço compreendido como um conceito-chave da Geografia e os demais, como conceitos estruturados dentro do espaço (SANTOS, 1978).

De acordo com Castells (1999), o espaço é a expressão da sociedade. A sociedade não apenas ocupa um espaço, mas cria espaços, modifica, atua, expressa no espaço sua realidade, ou seja, a sociedade é espaço e o espaço é sociedade. Santos (1978) vai além, ao afirmar que o espaço é um fato social, uma realidade objetiva. Para ele o espaço é um produto, isto é, o resultado da produção, "o espaço é um objeto social como qualquer outro." (1978, p.128). O autor argumenta que o espaço é um fato histórico, ele é:

simultaneamente produtor e produto; determinante e determinado; um revelador que permite ser decifrado por aqueles mesmos a quem revela; e, ao mesmo tempo em que adquire uma significação autêntica, atribui um sentido a outras coisas. Segundo essa acepção o espaço é um fato social, um fator social e uma instância social. (1978, p.130).

Quando o jogador atua sobre o espaço, ele acaba por marcá-lo de acordo com suas características, seus objetivos. Por exemplo, se ele desmata uma floresta deixando um vazio onde antes havia essa floresta, isso seria uma expressão de uma necessidade, a obtenção de madeira, que ficou marcada no espaço. Mas o espaço também exerce influência no sujeito, pois esse sujeito está no espaço e precisa se adaptar, até certo ponto, àquilo que o espaço lhe oferece. Por 
exemplo, o jogador se limitará na produção de seu exército de acordo com o que o espaço do jogo tem a lhe oferecer. Ele não poderá produzir certos soldados se não tiver ouro em seu território. Portanto o jogador precisa se adaptar ao que o jogo está lhe disponibilizando, por isso podemos afirmar que o espaço acaba por influenciar o sujeito. Como o espaço no jogo é simulado, nos referimos a ele como um Objeto Digital . O sujeito jogador expressa suas necessidades internas no desenrolar do jogo, mas não o faz sobre um espaço real e sim sobre uma simulação. O jogador colocará sobre a simulação a expressão dos Objetos Mentais na forma de Objetos Digitais produzindo o espaço.

Como um desmembramento do conceito de espaço, constatamos que o conceito de paisagem também está presente nojogo. Santos (1978) aponta que a abordagem tradicional coloca a paisagem como algo estático, deixando de lado a dialética do espaço. No jogo Age of Empires II, existe uma paisagem pré-definida, que é a tela inicial apresentada ao jogador. Com as possibilidades oferecidas pelo menu, o jogador pode interferir na paisagem, desmatando as árvores, explorando recursos minerais, construindo edificações etc., o que revela a dialética criada com a interferência humana (neste caso, o jogador) na paisagem. Dessa forma o jogador se vê na condição de sujeito que produz a paisagem, favorecendo a compreensão do conceito de paisagem como algo dinâmico, não estático.

Outro conceito que pode ser reconhecido a partir do jogo é o de região. O jogador, ao explorar o espaço, encontra recursos espalhados por todo o jogo; poderíamos definir a área em que se encontram estes recursos como região natural (Gomes, 2000). Para Gomes (2000), o conceito de região é marcado por uma diferenciação de áreas, podendo ser socialmente construí- das ou encontradas em seu estado natural. Observando o jogo, conseguimos destacar que são apresentadas inicialmente aos jogadores regiões naturais, que após serem dominadas e exploradas se transformam em uma segunda natureza, na qual cada jogador imprime suas necessidades e/ou opções. Entendemos que esse conceito de região está englobado pela concepção de território, pois o processo de ocupação e apropriação de uma determinada área envolve relações de domínio e poder, que acabam por configurá-las de acordo com a opção do jogador.

Quando iniciamos o jogo, é preciso indicar com qual povo se quer jogar (Romanos, Gregos, Bizantino, etc.). Durante o jogo são apresentadas civilizações que podem ser inimigas ou aliadas, dependendo da negociação do jogador. Porém um jogador nunca poderá jogar com o povo ou exército de outro jogador: ele opta por um povo e deve com esse povo construir um contexto para o jogo. Por meio da coleta e do uso de determinados produtos, espalhados em regiões do espaço, adquire-se certo poder para a construção de estruturas e aquisição de um exército. Para adquirir tais recursos, o jogador precisa localizá-los explorando o campo do jogo, na seqüência deve proteger o local descoberto para que seu inimigo não adquira os recursos explorados. Esse tipo de ação conduz o jogo e é nesse contexto de conflitos e domínios que reconhecemos a noção de território como sendo a mais marcante do jogo Age of Empires II, embora outras noções e conceitos estejam expressos nele, como vimos anteriormente.

O conceito de território pode ser identificado no jogo até mesmo pela terminologia "estratégia" empregada por jogadores e por revistas deste gênero de jogo. O termo estratégia é definido como:

arte militar de planejar e executar movimento e operações de tropas, navios e/ou aviões para 
alcançar ou manter posições relativas e potenciais bélicos favoráveis a futuras ações táticas. 2 . Arte de aplicar os meios disponíveis ou explorar condições favoráveis com vista a objetivos específicos. (FERREIRA, 1989, p.219)

Pode-se perceber uma grande semelhança entre a terminologia abordada acima e a concepção de território. Haesbaert e Limonad (1999) afirmam que o território é a apropriação e o domínio de um espaço socialmente partilhado. Para eles,

o território é uma construção histórica e, portanto, social, a partir das relações de poder (concreto e simbólico) que envolvem, concomitantemente, sociedade e espaço geográfico (que também é sempre, de alguma forma, natureza). (HAESBAERT e LIMONAD, 1999, p. 10)

Destacamos Lacoste (1989), em seu livro, “ A Geografia - Isso Serve, em Primeiro Lugar, Para Fazer a Guerra", que adota a terminologia "estratégia" relacionada ao uso do conhecimento geográfico para várias finalidades, inclusive militares. No livro, Lacoste trabalha esta terminologia referindo-se à Geografia com fins de domínio espacial. Constatamos que o domínio do espaço corresponde ao conceito de território.

Haesbaert e Limonad (1999) abordam unidades elementares dentro da concepção de território, que seriam áreas ou zonas, linhas e nós ou pontos. A estruturação dessas unidades forma uma rede territorial. As áreas ou zonas são elementos formados por uma geometria de linhas fundidas pelos nós, formando uma rede.

Usemos o jogo como exemplo. Para o jogador montar toda sua estrutura, ele precisa de elementos básicos, como pedra, ouro, madeira e alimento. De acordo com a necessidade, ele sai a explorar o campo do jogo em busca desses elementos, que, ao serem encontrados, deverão ser rapidamente protegidos e explorados, antes que o inimigo o faça. Como são encontrados vários pontos com essas matérias, o sujeito cria ligações entre a estrutura central e a matéria no campo.

Observamos a grande valorização tanto dos "recursos" quanto do conhecimento espacial, com destaque para "relevos" e "mapa". "Saber pensar o espaço para nele se organizar, para ali combater" (LACOSTE, p. 189, 1989). Conhecendo o espaço, o jogador terá a chance de dominá-lo. Com isso, terá a sua disposição os recursos que servirão para fortalecer sua estrutura e vencer a guerra.

A partir da observação do jogo, desenvolvemos o esquema da FIGURA 1, que revela a relação entre o jogador e seu inimigo no campo do jogo. Esse esquema permite a visualização das regiões (locais onde estão os recursos), das linhas (que ligam as regiões) e dos nós (pontos em que as linhas se cruzam). Os materiais encontrados próximo do centro são facilmente dominados pelo fato de o jogador ser o primeiro a explorar a região, aqui considerada como os locais onde encontramos os recursos naturais. Já a região mais longe dos dois jogadores fica sob o domínio daquele que chegar primeiro. O fortalecimento do jogador se dá por meio do acúmulo dos elementos à disposição, que ocorre quando o jogador explora rapidamente cada mina e um maior número delas. Quanto mais domínio, mais poder ele terá para fortalecer seu exército e dominar o inimigo. Para proteger cada área, o jogador precisa criar um exército que ficará patrulhando cada ponto de coleta.

Percebemos que a ligação feita entre o centro que arrecada todos os produtos e os pontos de coleta é a idéia de linhas e nós, que também é feita pelos soldados ao patrulharem cada área de coleta contra a invasão inimiga. Essa rede é formada pela apropriação e posterior domínio, dando idéia do conceito de território descrito por 
Haesbaert e Limonad (1999.). Constatamos assim a forte presença da noção de território no jogo, além da presença dos conceitos citados anteriormente.

Essa constatação possibilita o uso pedagógico dos conceitos, que podem ser discutidos pelos professores a partir das ações realizadas por alunos jogadores. sobre a Cartografia a responsabilidade de desenvolvimento simbólico espacial, ou seja, a criação de representações espaciais sobre um plano, que é a carta. Com relação à utilização da carta, esse autor afirma que "a carta é a forma de representação geográfica por excelência; é sobre a carta que devem ser colocadas todas as informações necessárias para a elaboração de táticas e de estratégias." (LACOSTE, 1989, p.23)

A organização do jogo está calcada em bases cartográficas, que conduzem e possibilitam os deslocamentos dos jogadores; dessa forma, procuramos reconhecer alguns elementos que demonstram a estrutura cartográfica do jogo.

\section{Símbolos}

Martinelli (1991) coloca os símbolos cartográficos como sendo um padrão adotado pela comunidade cartográfica

Dessa forma, acreditamos que o jogo pode ser um ótimo contexto de aprendizagem geográfica.

\section{Noções Cartográficas}

A relação entre a Cartografia e a Geografia é expressa por Francischett (1997), ao afirmar que a Geografia é a ciência que estuda o espaço, e que a Cartografia cria instrumentos os quais representam fenômenos no espaço geográfico estudado. Encontramos na Cartografia uma relação com a Geografia. Lacoste (1989) coloca mundial para fazer referência entre os objetos simbólicos presentes no mapa e os objetos da realidade. Martinelli (1991) também destaca que esses signos cartográficos contribuem para a comunicação entre os homens, ou seja, o homem criou signos que representam objetos na realidade e que são padronizados para facilitar o seu entendimento em diferentes comunidades. Francischett (1997) faz ligação entre os signos e a Cartografia, ao afirmar que esta é utilizada no ensino de Geografia para representar o espaço. Para essa autora, os mapas são dotados de simbologias, ou 
signos, representando a realidade. Ela afirma que a Cartografia cria representações da realidade para poder estudá-la, que o homem cria valores simbólicos para dar significado a objetos, convertendo-os em signos. Para Lévy (1999, p. 142), “os signos representam as coisas: tornam presentes as coisas ausentes."

Francischett (1997) afirma que a função da Cartografia para a Geografia seria a de representar o espaço através de símbolos, possibilitando a análise do espaço. No jogo, percebemos que os símbolos são ligados a determinadas ações. Dessa forma, identificamos esses símbolos como sendo os nós do hipertexto (ALBUQUERQUE; SÁ, 2000). Suas ações são determinadas pelos links que levam a determinado objetivo no jogo.

Podemos identificar um pequeno cartograma localizado no canto inferior direito do jogo, sendo visível a qualquer momento para o jogador. Chamamos esse elemento de cartograma baseado no que Soukup (1966) descreve. Este autor caracteriza os cartogramas como representações sintéticas e em pequenas escalas. Oferecem informações necessárias para uma rápida visualização. Um cartograma seria uma descrição espacial parecida com as cartas, mas que não oferecem informações mínimas para ser considerado uma carta como, por exemplo, legenda e escala.

O cartograma serve como referência para o jogador se localizar dentro do jogo. Ele demonstra todo o campo do jogo, onde pontos azuis representam o jogador, e os vermelhos e verde-claros seriam seus inimigos. Outras cores também se destacam nesse cartograma: o verde-escuro representando as árvores; pontos amareloescuros, jazidas de ouro; pontos cinza, jazidas de pedra; e toda porção azul-escuro, água. As partes em preto significam que o jogador ainda não explorou o lugar, portanto é desconhecido. Para se tornarem visíveis no cartograma, o jogador precisa mandar algum soldado ou escravo até o local. O uso de símbolos nesse cartograma assemelha-se à linguagem cartográfica, diferenciado no período de atualização. Esse cartograma é atualizado em tempo real, ou seja, as alterações que ocorrem no jogo são automaticamente registradas no cartograma.

Para Lacoste (1989, p.223):

deslocar-se num território que não é balizado (sem indicação de itinerário) e que não se conhece, ou que se conhece mal, exige se orientar e se informar para prever, antecipadamente, as distâncias, as dificuldades e os obstáculos. Se dispomos desse tão precioso meio de ação que é uma carta relativamente detalhada e se sabemos lê-la, o raciocínio geográfico é relativamente fácil.

Os símbolos, as cores e o próprio cartograma fazem parte da linguagem cartográfica trabalhada pelos professores de Geografia, e podem ser utilizados para a aprendizagem dos elementos fundamentais para leitura e mesmo confecção de cartogramas e mapas.

\section{Escala cartográfica}

No jogo também é perceptível a presença de uma variação de escalas. Descrevemos a escala de acordo com a seguinte fórmula: $\mathrm{E}=\mathrm{d} / \mathrm{D}$. Lacoste (1989) explica que a escala é a relação entre a distância real e a distância representada na carta, uma relação dimensional.

Essa fórmula não é apresentada no jogo como em um mapa, embora nos jogos possamos notar uma variação de tamanho, ocorrendo de forma padrão por todo o campo do jogo. Como já visto anteriormente, as representações utilizadas (cavaleiros, navios, soldados) são de 
tamanho reduzido em relação à realidade, e por isso também sofrem variação em sua escala. No jogo, apesar do não uso da fórmula da escala, utiliza-se outro método que permite variar as dimensões espaciais de visualização do jogo.

No menu de configuração do jogo existe uma opção chamada Screen Size, que faz a variação do tamanho da tela de visualização, como se alterasse a escala do campo do jogo. Mas, diferentemente das características da escala, os valores são dados em pixels. Essa ampliação e redução de tamanhos de visualização é o que de mais próximo da relação de escalas cartográficas encontramos no jogo, utilizando o pixel como padrão de medida.

Outro elemento do jogo remete à variação de escalas, a partir do pequeno cartograma já descrito. Constatamos a noção de escala apreendida a partir da relação entre a realidade do jogo e a representação da totalidade da área feita no cartograma. Neste, os objetos tornam-se apenas pontos, dificultando sua identificação, mas em compensação pode-se visualizar a localização do jogador em relação a seus oponentes. Isso é possível com a alteração de escalas.

Não existe qualquer valor no jogo que indique a relação de proporção entre o cartograma e a realidade representada por ele. Para Lacoste (1989), cada escala possui uma finalidade estratégica. Uma carta com escala pequena possui determinado enfoque operacional, enquanto que uma carta de grande escala possui outro enfoque. $O$ autor destaca que ambas são de grande utilidade para uma análise espacial.

Em relação à escala, constatamos que o jogo possibilita a compreensão da utilidade da escala e também de sua aplicação, o que pode contribuir para uma associação às escalas utilizadas em cartas e mapas escolares.

\section{Perspectiva: vertical, horizontal e oblíqua}

Com relação ao tipo de visão presente no jogo, observamos que a perspectiva oblíqua tem destaque. Ela está presente em todo o campo do jogo. Disperati (1995) a caracteriza como sendo planimétrica e altimétrica, tendo grande validade em reconhecimento e planejamento. Disperati (1995) destaca a possibilidade de visualização do terreno como bastante favorável quando se precisa ter idéia das dimensões de algo. Apesar da não existência dessas três dimensões no jogo, é perceptível algo parecido na Cartografia. Martinelli (1991) explica que a Cartografia é capaz de representar apenas $x$ e $y$, sendo que a profundidade $z$ é representada através de uma variação da tonalidade das cores. O mesmo pode ser observado no jogo, no qual se passa apenas uma sensação da profundidade, dada por meio de uma variação de cores.

Disperati (1995) coloca que esse tipo de visão, por passar uma sensação de tridimensionalidade, favorece o reconhecimento de campo: relevo, objetos vistos de perfil etc., acabando por se tornar de grande valor militar.

Podemos observar o uso da visão vertical no cartograma. Essa visão é muito adotada em mapas, a partir dos quais podemos chegar a medidas mais fidedignas por conta do uso das escalas. Apesar de não serem destacados os valores exatos desse cartograma, o jogador consegue localizar-se no espaço, pois o cartograma engloba todo o espaço explorado do jogo, passando uma sensação dimensional ao jogador.

A partir da análise do jogo, concluímos que muitas das noções e mesmo elementos que nele aparecem podem ser aplicados no processo de ensino-aprendizagem da Geografia. A riqueza de detalhes apresen- 
tada, criando contextos virtuais, permite simulações que proporcionam ao jogador o domínio de informações que o tornam agente no espaço. Como esses espaços são simulados ludicamente, percebemos um grande potencial interativo entre o sujeito jogador e o conhecimento trabalhado no meio.

\section{ALGUMAS CONSIDERAÇÕES}

A análise realizada a partir do Jogo Age of Empires II foi direcionada para um enfoque geográfico e ao mesmo tempo pedagógico. Geográfico, porque objetivamos revelar as noções que podem ser aprendidas/estudadas a partir desse jogo; pedagógico porque revela um potencial que pode ser utilizado pelo professor a partir das preferências de seus alunos.

O potencial oferecido por jogos de estratégia se torna mais uma fonte de recursos, advindos do informacional, que podem ser utilizados na educação formal. Novas linguagens revelam novas formas de leitura do espaço e, portanto, podem ser tratadas pelos docentes, pois o cotidiano dos alunos está cada vez mais repleto de tecnologias e de seus produtos.

$\mathrm{Na}$ análise desenvolvida, constatamos que a atuação do jogador no espaço simulado do jogo passa por diferentes conceitos geográficos, como os de espaço, território, paisagem e região, revelados durante a atuação do jogador no espaço simulado. Constatamos ainda elementos cartográficos e simbólicos presentes no jogo, o que revela sua potencialidade para o desenvolvimento de conceitos e noções cartográficas trabalhados pela escola. A simulação da realidade no jogo, feita por meio de símbolos, permite estabelecer comparações com a representação do espaço cartográfico (cartesiano), sendo possível a aproximação dos símbolos representados com suas sig- nificações na realidade observada. Com a era digital, foi possível hipertextualizar o espaço, permitindo que o sujeito interaja com ele. Essa possibilidade não surge nos patamares do ensino, mas nos alicerces da formação lúdica de um grupo identificado com uma cultura de jogos.

Porém deixamos de analisar outros aspectos, como a história dos povos presentes no jogo, que merece tratamento tanto da Geografia quanto de outras áreas de conhecimento, as quais, a partir de seus objetos de estudo, podem revelar novos saberes.

Além das noções geográficas, nossos estudos demonstraram a importância do conhecimento da origem desses produtos, os jogos. Reconhecer a ideologia criadora do jogo possibilita compreender sua proposta. Quem cria os jogos expressa fatores momentâneos que o levaram a contextualizá-los.

Outro aspecto a ser destacado é a caracterização dos grupos receptores de tais jogos, pois aqueles interpretam o jogo de acordo com a sua cultura, porém o jogo torna o indivíduo um sujeito híbrido, a partir da assimilação de outras culturas.

$\mathrm{Na}$ atualidade, o papel do professor é propiciar o desenvolvimento de cidadãos conscientes. Nesse sentido, buscamos apresentar neste estudo uma ferramenta para o professor utilizar no processo de formação de seus alunos.

\section{REFERÊNCIAS}

ALBUQUERQUE, A.; SÁ, S. P. Hipertexto, jogos de computador e comunicação. FAMECOS, Porto Alegre, n. 13, p. 83-93, dez. 2000.

ANDRADE, H.; CORREIA, C. Noções básicas de hipertexto. Disponível em < http:/ / www.facom. ufba.br/hipertexto/nbasicas2.html >. Acesso em: 21 out. 2004.

BOURDIEU, P. A economia das trocas simbólicas. São Paulo: Perspectiva, 1998. 
Alides Baptista Chimin Junior e Carla Silvia Pimentel

CASTELLS, M. A sociedade em rede. São Paulo: Paz e Terra, 1999.

CASTRO, I. E.; GOMES, P. C. C.; CORRÊA, R. L. Geografia: conceitos e temas. 2 ed. Rio de Janeiro: Bertrand Brasil, 2000.

CHATEAU, J. O jogo e a criança. São Paulo: SUMUS, 1987.

CHIMIN JUNIOR, A. B. Jogos de estratégia de computador: hipertextualizando a geografia. Trabalho de conclusão de curso (Geografia) - Universidade Estadual de Ponta Grossa, Ponta Grossa, 2005.

CHOMSKY, N. Mídia, terrorismo e (des)informação. FAMECOS, Porto Alegre, n. 22, p. 117-124, dez. 2003.

O que o Tio Sam realmente quer. Brasília: Universidade de Brasilia, 1999.

DISPERATI, A. A. Fotografias aéreas inclinadas. Curitiba: UFPR, 1995.

FERREIRA, A. B. H. de. Estratégia. In: Minidicionário da Língua Portuguesa. Rio de Janeiro: Nova Fronteira, 1989.

FILHO, O.; PELEGRINO, E. História do hipertexto. Disponível em < http://www.facom.ufba.br/ hipertexto/historia.html >. Acesso em: 2004.

FRANCISCHETT, M. N. A cartografia no ensino da geografia. Francisco Beltrão: Grafit, 1997.

FREIRE, P. Pedagogia do oprimido. Rio de Janeiro: Paz e Terra, 1982.

HAESBAERT, R.; LIMONAD, E. O território em tempos de globalização. Geo UERJ Revista do Departamento de Geografia. Rio de Janeiro, n. 5, p. 7-19, 1 sem. 1999.

IBGE, Dados Censitários 2000. Disponível em: < http://www.ibge.gov.br >. Acesso em: 19 fev. 2005.

KELLNER, D. A cultura da mídia. Bauru: EDUSC, 2001.

Mídia, terrorismo e (dês) informação. FAMECOS, Porto Alegre, n. 22, p. 117-124, dez. 2003.

A crítica de Nietzsche à cultura de massa. FAMECOS, Porto Alegre, n. 13, p. 12-22, dez. 2000.

KERCKHOVE, D. Texto, contexto e hipertexto: três condições da linguagem, três condições da mente. FAMECOS, Porto Alegre, n. 22, p. 7-22, dez. 2003.
LACOSTE, Y. Geografia: isso serve, em primeiro lugar para fazer a guerra. São Paulo: Papirus, 1989.

LÉVY, P. Semiótica. A inteligência coletiva: por uma antropologia do Cyberespaço. São Paulo: Loyola, 1999.

\section{1.}

. O que é o virtual? São Paulo: Edições 34,

MARTINELLI, M. Curso de cartografia temática. São Paulo: Contexto, 1991.

MENDES, L. M. Controla-me que te governo: os jogos eletrônicos como forma de subjetivação. Educação e Realidade, Porto Alegre, v. 26, n. 1, p. 125-139, jan./jun. 2001.

MORAN M. J. Leitura dos meios de comunicação. Vila Buarque: Pancast, 1993.

PILLAS, J. M. Nossos agentes em Havana. Rio de Janeiro: Record, 1996.

RANDOLPH, R.; TRINDADE, M. H. L. Digital divide: reflexões sobre novas formas de exclusão social. Geografares, Vitória, v. 1, n. 1, p. 89-107, jun. 2000.

RIBEIRO, L. Comunicação global. Rio de Janeiro: Objetiva, 1993.

SANTOS, J. F. Breve, o pós-humano. Curitiba: Francisco Alves, 2002.

SANTOS, M. Por uma geografia nova. São Paulo: Hucitec, 1978.

SILVA, C. A. F.; TANCMAN, M. A dimensão socioespacial do ciberespaço: uma nota. Geographia, Rio de Janeiro, v. 1, n. 2, p. 55-66, 1999.

SOUKUP, J. Ensaios cartográficos. São Paulo: Revista dos Tribunais, 1966.

TOPGAMES. São Paulo, v. 2, n. 9, 1999.

Recebido em 01/11/2009

Aceito em 15/12/2009 